\title{
IMPACT OF SALESPERSONS' SKILL-SETS ON SALES PERFORMANCE: AN EMPIRICAL INVESTIGATION OF A TELECOMMUNICATION COMPANY
}

\author{
Kashif Shafiq \\ Assistant Professor, Institute of Business Management \\ Muhammad Waqas \\ Lecturer Economics, DHA Suffa University \\ Arslan Rafi \\ PhD Scholar, Preston University
}

\begin{abstract}
Purpose: The objective of this research article is to find out the impact of customer orientation, adaptive selling, and emotional intelligence on sales performance. Personal selling is said to be happened when a solution to the problems regarding sales, services and customers is provided by a sale representative.

Methodology: It is the skill and duty of the sale representative to provide his services which provide a best match with the requirements of the customers. Total 100 questionnaires were distributed among the employees of a telecommunication company.

Findings: Results show that: Salespersons who apply customer orientation are more successful in the market and Salespersons that are more adaptive in several selling situations have more competitive edge over less adaptive salespersons.

Implication: Both customer orientation and adaptive selling would be high if a salesperson possesses emotional skills. Therefore, it is recommended that recruiter should hire salespersons with high acumen on customer orientation, adaptive and emotional skills.
\end{abstract}

Keywords: Customer Orientation, Adaptive selling, Emotional Intelligence, Sales Performance Management, Training and Development

Jel Classification: J18, J28, J29

*The material presented by the author does not necessarily portray the view point of the editors and the management of the Ilma University - Formerly IBT

1. Kashif Shafiq : Kashif.shafiq@iobm.edu.pk

2. Arslan Rafi: arsalanrafi@gmail.com

3. Muhammad Waqas.: Muhammad.waqas@dsu.edu.pk

CILMA-JBS is published by the Ilma University - Formerly IBT

Main Ibrahim Hydri Road, Korangi Creek, Karachi-75190, Pakistan 


\section{INTRODUCTION}

Salespersons sell a product; give service, or solution against a problem that is called personal selling. Personal selling is the most effective marketing tool these days because of its dynamic benefits. First of all salesperson has a chance to directly involve with the customer and make him convince for company's products and services.

Therefore, salesperson's role is very critical here because he is the one who taking company's image to the market by doing direct selling. When client's condition of feelings effectively distinguished, salespersons can utilize their own particular feelings to encourage clients' aims (Zablah, Franke, Brown, \& Bartholomew, 2012). Encouraging feelings is the most imperative measurement on the grounds that in first measurement salesmen are breaking down clients' feelings, then salespersons need to choose his own particular feeling precisely (Matthews, Zeidner, \& Roberts, 2001). Particularly in advertising trades it is first to separate feelings and recognizes what feeling is reasonable in that specific circumstance. Salespersons with more elevated amounts of emotional intelligence see feelings, and afterward see how fitting feeling can influence clients' buying goals (Jasmand, Blazevic, \&Ruyter, 2012).

Understanding feelings is to distinguish complex feelings and create emotional information (Shah, Kumar, \& Chen, 2012). It includes understanding complex feelings that how distinctive feelings lead to nervousness or resentment, and how these feelings change collaborations with clients. All in all, overseeing feeling is the bent to control feelings of others and yourself to accomplish productive results (Roberts \& Grover, 2012). In promotional activities, sales representative with larger amount of emotional intelligence is better separate among positive and negative feelings. It relies upon clients' perspective and compelling salespeople have this capacity to comprehend clients' unpredictable feelings and after that utilization their own feelings to make joined them towards their items and administrations.

Individuals have distinctive sort of emotional learning, contingent on their emotional capacities, which is inborn or created by parental backing in the youth. An individual's capacity to use emotional data can specifically impact cooperation's. Envisioned comprehension upgrades the business agent capacity in addressing and satisfying client's needs (Homburg, Bornemann, \& Wieseke, 2009). Several examinations ponders recognized, specific emotional capacities give better comprehension of feelings \& give a rule that how to utilize these feelings in offering circumstances (Palmatier et al., 2009).

\section{LITERATURE REVIEW}

\subsection{Customer Orientation}

The most important construct in salespersons performance is customer orientation. Several studies have been conducted on customer orientation with reference to sales performance (Park \& Franke, 2006). Noteworthy issue in overseeing deals power is the means by which to upgrade sales representative's execution. This vital yet unexplored inquiry is particularly applicable amid the current financial decay, as organizations attempting to propel their efficiency to stay focused, among rising deals expenses \& declining clients' enthusiasm for buy decisions. An assortment of items accessible in the business sector, client 
has diverse options accessible, in this specific circumstance sales representative must be more talented so as to adapt to current conditions. Customer orientation is a vital construct in marketing literature. Businessperson with rich learning of Customer orientation will probably see clients' needs, satisfy clients' request, and settling clients' difficulties. Customer orientation comes about as win-win circumstances, the purpose for each client is entertained by particular needs, creating abnormal state of execution for both association and deals drive it.

This vital yet unexplored inquiry is particularly applicable amid the current financial decay, as organizations attempting to propel their efficiency to stay focused, among rising deals expenses \& declining clients' enthusiasm for buy decisions. An assortment of items accessible in the business sector, client has diverse options accessible, in this specific circumstance sales representative must be more talented so as to adapt to current conditions. Meta-examination recommended direct noteworthy effect on deals execution, paying little respect to what execution measuring instruments is utilized. The meta-investigation comes about demonstrates that the fleeting impact of Customer orientation on deals execution is not perceived in the business income or by the top administration, however it could upgrade the long haul deals execution (Park \& Franke, 2006). In the event that, haul effect of Customer orientation prompts high consumer loyalty (Stock \& Homburg, 2005), client's energy to manage his or her long haul association with the businessperson \& association. Extra plausibility is that the effect of Customer orientation on execution by the interceding part of versatile undercutting can improve the term deals execution.

\subsection{Adaptive Selling}

The term of adaptive selling categorized as the moving of offers practices while a business experience or amid client cooperation's reliant on maintained data about the sort of the communication circumstance (Weitz \& Sujan, 1986). Salesman utilizes abnormal state of adaptive selling when they join a few deals presentations while deals experiences, besides they make changes amid selling conditions. At the end of the day, sales representative with low level of adaptive selling is assigned by the routine of utilizing same old styled deals presentations amid all business experiences. Adaptive selling can be begun in a productive \& a wasteful way; subsequently, effectiveness is not identified with the genuine meaning of versatile offering. Adaptive selling brings about long haul achievement when the paybacks of the system exceed the real cost. At the point when the deals made through the usage of adaptive selling exceed the expense of picking \& preparing sales representative to accumulate proper data from their objective clients \& utilizing this suitable data precisely.

Benefits exceed the expenses under four sorts of various conditions 1) salesman meet diverse clients having diverse arrangement of requirements, 2) the unmistakable deals conditions comes about as in vast requests 3 ) the association offers assets to rearrange adjustment, \& 4) the businessperson can adjust effectively (Weitz \& Sujan, 1986).

\subsection{Emotional Intelligence}

Seeing feelings is the capacity to perceive \& translate feelings precisely (Caruso \& Mayer, 1999). Seeing feelings is the capacity to separate diverse sorts of feelings. Particularly it is imperative for deals experts to better see clients' feelings that are he or she is exhausted 
or energized, confounded or intrigued, such separation give deals experts to choose techniques likewise.

When client's condition of feelings effectively distinguished, salespersons can utilize their own particular feelings to encourage clients' aims (Salovey \& Mayer, 1997). Encouraging feelings is the most imperative measurement on the grounds that in first measurement salesmen are breaking down clients' feelings, then salespersons need to choose his own particular feeling precisely (Matthews, Zeidner, \& Roberts, 2001). Particularly in advertising trades it is first to separate feelings \& recognizes what feeling is reasonable in that specific circumstance. Deals experts with more elevated amounts of emotional intelligence see feelings, \& afterward see how fitting feeling can influence clients' buy goals.

Understanding feelings is to distinguish complex feelings \& create emotional information (Salovey \& Mayer, 1997). It includes understanding complex feelings that how distinctive feelings lead to nervousness or resentment, \& how these feelings change collaborations with clients. All in all, overseeing feeling is the bent to control feelings of others \& yourself to accomplish productive results (Salovey \& Mayer, 1997). In promoting trade, sales representative with larger amount of emotional intelligence is better separate among positive $\&$ negative feelings. It relies on upon clients' perspective $\&$ compelling deals experts have this capacity to comprehend clients' unpredictable feelings \& after that utilization their own feelings to make joined them towards their items and administrations.

\subsection{Customer Orientation \& Sales Performance}

Customer orientation is the method for the promoting thought at the level of the salesman \& target client. Customer orientation is an apparatus utilized by sales representative, which alludes to the level to which sales representative can adequately take an interest in client's buy decision to settle on his or her decision about acquiring item. Client Oriented sales representative will probably participative \& dynamic while communicating with clients. Businesspersons who have more elevated amount of Customer Orientation dependably attempt to stay away from such activities, which prompts client disappointment. The first formalization of Customer orientation began when Weitz and Saxe (1982) suggested that sales representative for the most part utilize the greater part of these different circumstances, the principal circumstance happens where businessperson more centered on offering exercises, the principle thought here is just to deal the item. The second circumstance is the place deal individual is more worried about client behaviour, here salesmen just need to make a deal as well as to grow long haul beneficial association with the client. In the end offering introduction is to make a deal, which is a transient target while Customer orientation accentuation on client needs to offer item that satisfies client need bitterly.

\subsection{Adaptive Selling \& Sales Performance}

The term of adaptive selling characterized as the moving of offers practices while a business experience or amid client associations subject to purported data about the sort of the cooperation circumstance (Weitz \& Sujan, 1986). Sales representative utilize an abnormal state of adaptive selling when they consolidate a few deals presentations while deals experiences, besides they make alterations amid selling circumstances. At the end of the day, sales representative with low level of adaptive selling is assigned by the routine of utilizing same old styled deals presentations amid all business experiences. 
Spiro and Weitz (1990), build up the thought further in their clarification of the adaptive selling. They guarantee that the paybacks of adaptive selling practices, Adaptive selling brings about long haul achievement, when the helps of the procedures equalization costs. At the point when deal made through the assistance of adaptive selling, it comes about as in long haul benefit for both the gatherings. In the end adaptive selling improves individual's capacity of gathering important data from target clients \& utilizes this data legitimately. Adaptive selling overweighs the expenses as far as when the business delegate has the required assets, when arrangements are mind boggling \& may bring about huge volume, \& when clients has less clashes on arrangements eventually comes about as in long haul connections between the organizations \& the clients. On the other $\mathrm{h} \&$, even in straightforward deals experiences if basic procedures are joined, responses to inquiries, non-verbal communication \& remarks diminish protests from purchaser's side. Thus, inquires about firmly stressed that adaptive selling practices improves deals agent's execution regardless of circumstances (Goolsby, Boorom, \& Ramsey, 1992). Adaptive selling upgrades the business execution. Moreover, the business agent's capacity to utilize in adaptive selling, might be dominatingly critical in building \& keeping up long haul associations with clients (Jolson, 1997) thus could be a noteworthy capacity to support deals execution. Marshall et al., (2003) recommend that business officials rank the business agent's ability to utilize adaptive selling as the top most deals experience's expertise. Adaptive selling is basic to sales representative execution since purchaser merchant connections are discernibly bolstered when sales representatives go to the clients encourage by adjusting the business methodology to address client's issues (Holloway $\&$ Park 2003). Various studies have associated adaptive selling to target indications of execution (Fang, \& Evans, 2004).

\subsection{Emotional Intelligence \& Sales Performance}

Individuals nowadays are exceptionally worried about how feelings impact the decisions they make in regular day to day existence. Utilizing feelings is the developing marvel in recent years (Goleman, 1995).Emotional Intelligence has increased broad universal consideration from most recent fifteen years (Matthews, Zeidner, \& Roberts, 2001). Utilizing feelings \& translate them has gotten to be key sympathy toward purchasers \& dealers \& venders utilize the emotional part of purchasers for selling their items by making the item altered to the feelings of the clients or by promoting the item in an emotionally engaging way. Late figures uncover that top multinational associations are centering to upgrade emotional intelligence capacities of their representatives extraordinarily salespersons (TalentSmart, 2009). Moreover, more multinational organizations are included to sort out preparing projects to upgrade emotional intelligence capacities among their representatives. In the long run it has ended up crucial for organizations that they ought to better comprehend this capacity that how this capacity can impact advertising trades. Further, Study will talk about measurements of Emotional Intelligence. 


\subsection{Thoertical Framework}

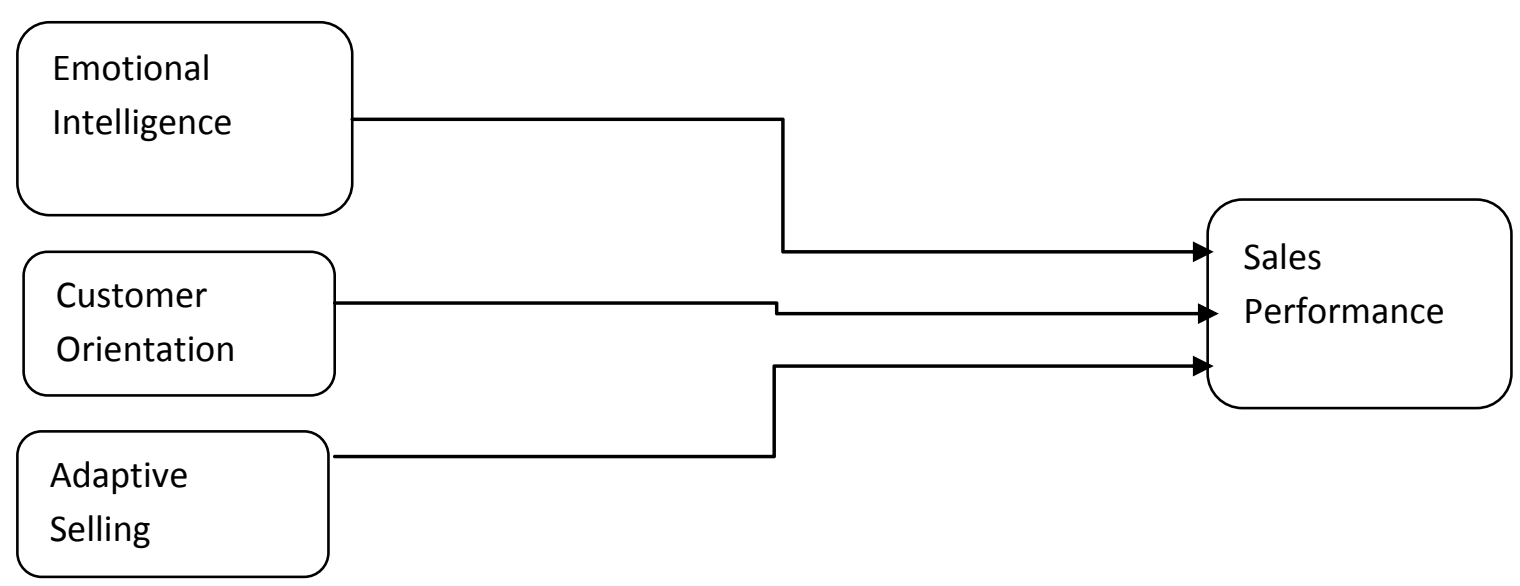

Figure.1: Proposed Research Model

\section{Hypothesis}

H1: Salesperson with higher customer orientation will produce better sales performance.

H2: Salesperson incorporating adaptive selling techniques will produce better sales performance.

H3: Salesperson having emotional intelligence will produce better sales performance.

\section{METHODOLOGY}

This research study is based on hypothetical deductive approach. Which starts with the extensive literature review, problem identification, research questions, research objectives results and analysis. Furthermore, positivism philosophy will be applied which is based on quantitative technique. The population of this research study is includes the sales and sales related personnel of a particular telecommunication company. Sample consists of salespersons working in Telecommunication Company. Research instrument and measurement scale details shows that Emotional Intelligence is measured with 15-items scale taken from (Kidwell et al., 2011) whereas, customer orientation's 12 items-scale is taken from a study of (Saxe \&Weitz, 1982). Adaptive selling scale is consisting of 7-items scale which is taken from (Spiro \&Weitz, 1990). Lastly, sales performance is measured with 6items scale given by.

\subsection{Demographic details}

The total number of 100 questionnaires is distributed among the target sample. In which were usable for data analysis it means that survey has shown $100 \%$ response rate.

Demographic profile of the sample $(N=100)$

\begin{tabular}{|c|c|c|}
\hline Demographic Variable & F & \% \\
\hline Gender & & 69 \\
\hline
\end{tabular}


Journal of Business Studies - JBS Vol.13 Issue.2, December 2017

\begin{tabular}{|c|c|c|}
\hline Female & 31 & 31 \\
\hline $20-25$ & & 77 \\
\hline $25-30$ & 77 & 20 \\
\hline $30-35$ & 20 & 3 \\
\hline
\end{tabular}

\subsection{Reliability}

Reliability is how much questionnaire is reliable for collecting data. Reliability of questionnaires is examined through Cronbach's Alpha. The recommended values are 0.6 to 0.8 (Hair et al., 2006).

\begin{tabular}{|l|l|l|l|}
\hline Variables & Cronbach's Alpha & KMO & Items \\
\hline Emotional Intelligence & .696 & .744 & 15 \\
\hline Customer Orientation & .710 & .786 & 12 \\
\hline Adaptive Selling & .657 & .818 & 7 \\
\hline Sales Performance & .775 & .792 & 6 \\
\hline
\end{tabular}

\subsection{Pearson's Correlation}

Correlation shows how much strong the relationship between two or more variables is and tells how much these variables are related to each other (Sekaran, 2006). Correlation tells the strength of the relationship of independent and dependent variables. Pearson correlation is used in this matter.

\begin{tabular}{|l|l|l|l|l|l|}
\hline & & EI & CO & AS & SP \\
\hline EI & Emotional Intelligence & 1 & & &. \\
\hline CO & Customer Orientation & .016 & 1 & & \\
\hline AS & Adaptive Selling & .068 & .019 & 1 & \\
\hline SP & Sales Performance & $.257^{* *}$ & $.517^{* *}$ & $.635^{* *}$ & 1 \\
\hline
\end{tabular}

\section{DISCUSSION}

Role of emotions with respect to exchange relationship were under consideration by many researchers (Bagozzi, Gopinath, and Nyer 1999; Gustafsson, Johnson, and Roos 2005), and a number of questions were posed by them to find out the impact of emotions on customers but they are not properly answered. It is identified in this present research that marketing literature has not been properly understood. An important variable is emotional intelligence which can provide better picture about interaction of sales professionals with their customers. With the help of it we can not only come to know the way these interactions are facilitated but also means of getting improved outcome. Purported benefits of EI given by (Goleman, 1995) generated much excitement but due to the conspicuous shortcomings theoretical development became limited. 
According to Zeidner, Matthews, and Roberts (2004) findings of Prior domain-general EI have been found equivocal. Based on the present research it ids identified that in relation to these prior findings, there are some specific domains for instance, marketing exchange about which predicting capacity of domain general assessment is limited. In this study it is stated that contingency effect of EI is of vital importance in marketing exchange as it affects the performance directly. It is also indicated in this research that people with high EI, is more customer oriented and have more ability to influence their customers. It is also found out that EI plays role of moderator in the relationship of sales professionals and their customers. It also suggests that if sales professionals actually want to employ techniques for better customer interaction, then their emotional abilities are of vital importance. Due to these findings we can state that apart from training given to sales professionals for better interaction with customers, high EI is an essential factor which can help them in implementing techniques in far better way. So we can conclude that with the help of high EI successful selling behavior of sales professionals can be obtained.

\section{SUMMARY OF FINDINGS}

Present research is aimed at finding out the impact of Emotional intelligence on customer orientation. It also focuses on the sales personals under adaptive selling. Personal selling is said to be happened when a solution to the problem regarding sales, services and customer is provided by a sale representative. It is the skill and duty of the sale representative to provide his services which provide a best match with the requirements of the customers. We all are aware that sales are the main instrument which generate revenue and fulfills the organization's goal and to attain this goal we have to do our best to satisfy our customers' need. Customer's need may cover all different aspects such as behavioral, psychological as well as cultural. If an organization wants to make difference with its competitors then sales force should be utilized and polished to get competitive advantage. When we are talking about customer relation then our focus should be on sale force so that company's survival is possible.

It is highlighted by (Jaramillo et al., 2005) that as the procedure and function of the organization goes on, it become more difficult to find out the dimension based on which performance can be measured which makes sales process more complex. Here it is very important to notice that objective of salesperson is not just to boost sales to increase revenue but to build a strong and long term relation with their customers by fulfilling their demand so that they become loyal and connected for a long time. According to Marshall and Johnston (2009) in these situations assessment of salesperson's performance becomes difficult. To overcome these problems we are in in need of some additional measurements so that performance of salespersons can be assessed. Today main difficulty in performance assessment is that we are unaware of the set of skills which can give a clear picture of salesperson's performance.

(Spiro et al., 2008) states that salespersons who are competitive in nature, self-motivated, highly enthusiastic and aggressive can get their performance assessed as for such salespersons we are provided with fully designed structure which can make this easier. In selling procedure first of all customers are targeted for whom we want to serve, after this their needs and demand are identified to get a clear picture of what they want from us. After identification strategies are made and developed in best way which has a perfect match in serving customers. Next level is to convey messages for the incorporation of these strategies and then alterations are made if needed, so that positive influence can be enhanced. This step 
by step process enables the salespersons to focus on particular customers so that they become familiar with their needs and provide better and appropriate services to fulfill them. In this way each customer get proper attention individually and feels valued. Feedback is an important factor that helps the salespersons to develop their strategies and making alteration in them.

Marketing is emerging a lot nowadays which leads to higher sales and its important tools are media, purchase displays, promotions as well as packaging which attract customers. With the help of these tools, specific audience can be captured. Due to this restriction it becomes difficult to get proper feedback as interruptions occurred in delivery of messages regarding sales. This problem can be overcome by using personal selling aspect. But it may cost higher. From perspective of firm as well researchers and management, this tool is of vital importance to enhance the salesperson's performance. We can conclude here that sales executive should focus on the selection of their sales force, giving them better training and then organizing them to get them better performed. On the other hand focus of sales researchers should be to provide a framework depending upon which performance of salespersons can be evaluated and enhanced.

\section{REFERENCES}

Alex R. Zablah, George R. Franke, Tom J. Brown, \& Darrell E. Bartholomew, (2012). How and When Does Customer Orientation Influence Frontline Employee Job Outcomes? A Meta-Analytic Evaluation. Journal of Marketing, Vol. No. 76. 21-40.

Bagozzi, Richard P1.., Mahesh Gopinath, \& Prashanth U. Nyer, (1999). The Role of Emotions in Marketing. Journal of the Academy of Marketing Science, 27 (2), 184206.

Blair Kidwell, David M. Hardesty, Brian R. Murtha, \& Shibin Sheng, (2011). Emotional Intelligence in Marketing Exchanges, Journal of Marketing, 78 -95.

Claudia Jasmand, Vera Blazevic, \& Ko de Ruyter, (2012). Generating Sales While Providing Service: A Study of Customer Service Representatives' Ambidextrous Behavior. Journal of Marketing, Vol. No. 76. 20-37

Denish Shah, V. Kumar, Yingge Qu, \& Sylia Chen, (2012). Unprofitable Cross-Buying: Evidence from Consumer and Business Markets. Journal of Marketing, Vol. No. 76. 78-95

Franke, George R. \& Jeong-Eun Park, (2006). Salesperson Adaptive Selling Behavior and Customer Orientation: A Meta-Analysis. Journal of Marketing Research, 43 (November), 693-702.

Fang, Eric, Robert W. Palmatier, \& Kenneth R. Evans, (2004). Goal-Setting Paradoxes? Trade-Offs Between Working Hard and Working Smart: The United States Versus China. Journal of the Academy of Marketing Science, 32 (Spring), 188-202.

Goolsby, Jerry R., Rosemary R. Lagace \& Michael L. Boorom, (1992). Psychological Adaptiveness and Sales Performance. Journal of Personal Selling and Sales Management, 12 (Spring), 51-66.

Goleman, D., (1995). Emotional Intelligence. Bantam Books, New York, NY.

Gustafsson, Anders, Michael D. Johnson, and Inger Roos (2005), “The Effects of Customer Satisfaction, Relationship Commitment Dimensions, and Triggers on Customer Retention," Journal o/f Marketing, 69 (October), 210-18.

Homburg, Christian, Jan Wieseke, \&TorstenBornemann, (2009). Implementing the Marketing Concept at the Employee- Customer Interface: The Role of Customer Need Knowledge. Journal of Marketing, 73 (July), 64-81. 
Jolson, M., (1997). Broadening othe scope of relationship selling. Journal of Personal Selling and Sales Management, 75-88.

Johnston, M.W., \& Marshall, G.W., (2009). Sales Force Management, 9th ed., McGraw-Hill, New York, NY.

Mayer, J.D., Caruso, D.R., \& Salovey, P., (1999). Emotional intelligence meets traditional standards for intelligence, 267-98.

Mayer and Salovey, P., (1997). Emotional intelligence meets traditional standards for intelligence, 267-98.

Marshall, G., Goebel, D., \& Moncrief, W., (2003). Hiring for success at the buyer-seller interface. Journal of Business Research, 247-55.

Nicholas Roberts and Varun Grover, (2012). Leveraging Information Technology Infrastructure to Facilitate a Firm's Customer Agility and Competitive Activity: An Empirical Investigation. Journal of Management Information Systems. Vol. No. 28, No. 4. Pp. 231-269

Palmatier, Robert W., Cheryl Burke Jarvis, Jennifer R. Bechkoff, \& Frank R. Kardes, (2009). The Role of Customer Gratitude in Relationship Marketing. Journal of Marketing, 73 (September), 1-18.

Park, \& Betsy B. Holloway, (2003). Adaptive Selling Behavior Revisited: An Empirical Examination of Learning Orientation, Sales Performance, and Job Satisfaction. Journal of Personal Selling \& Sales Management, 23(3), 239-251.

Roberts, Richard D., Moshe Zeidner, \& Gerald Matthews, (2001). Does Emotional Intelligence Meet Traditional Standards for an Intelligence? Some New Data and Conclusions, Emotion, 1 (3), 196-231

Roberts, Richard D., Moshe Zeidner, \& Gerald Matthews, (2001). Does Emotional Intelligence Meet Traditional Standards for an Intelligence? Some New Data and Conclusions, Emotion, 1 (3), 196-231.

Stock, R.M., \& Hoyer, W.D., (2005). An attitude-behavior model of salespeople's customer Orientation. Journal of the Academy of Marketing Science, pp. 536-52.

Sujan, Harish \& Barton Weitz, (1986). The Effects of Level and Type of Effort on Salesperson Performance, working paper, Pennsylvania State University.

Sujan, Harish \& Barton Weitz, (1986). The Effects of Level and Type of Effort on Salesperson Performance, working paper, Pennsylvania State University.

Saxe, R. and Weitz, B.A., (1982). The SOCO sale: a measure of the customer orientation of salespeople. Journal of Marketing Research, 343-51.

Sujan, Harish \& Barton Weitz, (1986). The Effects of Level and Type of Effort on Salesperson Performance, working paper, Pennsylvania State University.

Sekaran, U. 2006, Research Methods for Business: A Skill Building Approach, 4th edn, John Wiley and Sons, New Delhi.

Spiro, RosAnn L., \& Barton A. Weitz, (1990). Adaptive Selling: Conceptualization, Measurement, and Nomological Validity. Journal of Marketing Research, 27 (February), 61-69.

Talentsmart, (2009). The Business Case for Emotional Intelligence, (accessed June 1, 2009). 